\title{
BMJ Open Risk factor modifications and depression incidence: a 4-year longitudinal Canadian cohort of the Montreal Catchment Area Study
}

\author{
Xiangfei Meng, ${ }^{1,2}$ Alain Brunet, ${ }^{1,2}$ Gustavo Turecki, ${ }^{1,2}$ Aihua Liu, ${ }^{2}$ Carl D'Arcy, ${ }^{3,4}$ \\ Jean Caron ${ }^{1,2}$
}

To cite: Meng $X$, Brunet $A$, Turecki G, et al. Risk factor modifications and depression incidence: a 4-year Iongitudinal Canadian cohort of the Montreal Catchment Area Study. BMJ Open 2017;7:e015156. doi:10.1136/ bmjopen-2016-015156

- Prepublication history and additional material are available. To view these files, please visit the journal online (http://dx.doi.org/ 10.1136/ bmjopen-2016-015156).

Received 11 November 2016 Revised 20 March 2017 Accepted 4 April 2017

${ }^{1}$ Department of Psychiatry, McGill University, Montreal, Quebec, Canada

${ }^{2}$ Douglas Mental Health University Institute, Montreal, Quebec, Canada

${ }^{3}$ Department of Psychiatry, University of Saskatchewan, Saskatoon, Saskatchewan, Canada

${ }^{4}$ School of Public Health University of Saskatchewan, Saskatoon, Canada

Correspondence to Dr Xiangfei Meng; xiangfei.meng@mcgill.ca

\section{ABSTRACT}

Objective Few studies have examined the effect of risk factor modifications on depression incidence. This study was to explore psychosocial risk factors for depression and quantify the effect of risk factor modifications on depression incidence in a large-scale, Iongitudinal population-based study.

Methods Data were from the Montreal Longitudinal Catchment Area study ( $\mathrm{N}=2433)$. Multivariate modified Poisson regression was used to estimate relative risk (RR). Population attributable fractions were also used to estimate the potential impact of risk factor modifications on depression incidence.

Results The cumulative incidence rate of major depressive disorder at the 2-year follow-up was $4.8 \%$, and $6.6 \%$ at the 4 -year follow-up. Being a younger adult, female, widowed, separated or divorced, Caucasian, poor, occasional drinker, having a family history of mental health problems, having less education and living in areas with higher unemployment rates and higher proportions of visible minorities, more cultural community centres and community organisations, were consistently associated with the increased risk of incident major depressive disorder. Although only $5.1 \%$ of the disease incidence was potentially attributable to occasional drinking (vs abstainers) at the 2-year follow-up, the attribution of occasional drinking doubled at the 4-year follow-up. A $10 \%$ reduction in the prevalence of occasional drinking in this population could potentially prevent half of incident cases.

Conclusions Modifiable risk factors, both individual and societal, could be the targets for public depression prevention programmes. These programmes should also be gender-specific, as different risk factors have been identified for men and women. Public health preventions at individual levels could focus on the better management of occasional drinking, as it explained around 5\% 10\% of incident major depressive disorders. Neighbourhood characteristics could also be the target for public prevention programmes. However, this could be very challenging. A cost-effectiveness analysis of a variety of prevention efforts is warranted.

The Global Burden of Disease Study 2010 reported depression is a major public health

\section{Strengths and limitations of this study}

- This study used a large longitudinal populationbased study to explore risk factors for incident depression.

- The study provides quantitative measures on the potential effects of risk factor modifications on depression incidence.

- The study sample was not representative of the initial survey sample.

- It is difficult to know how much we could achieve on disease reduction when a single risk factor is removed.

problem. ${ }^{1}$ The increasing burden of depression tax healthcare systems as they strive to meet the rising needs. ${ }^{23}$

Many cross-sectional and longitudinal studies have consistently found the following mostly psychosocial factors are associated with the increased risk of major depressive disorder: the use of alcohol, tobacco and drugs during pregnancy, ${ }^{4}$ maternal stress, ${ }^{5}{ }^{6}$ low birth weight, ${ }^{7}$ child abuse and adverse childhood experience, ${ }^{8} 9$ low income,${ }^{10}$ unemployment, ${ }^{11}$ smoking, ${ }^{12}$ physical inactivity, ${ }^{13}$ unhealthy eating styles, ${ }^{14}$ low social support, stressful events and neighbourhood deprivation.

The prevalence and incidence of depression are increasing. ${ }^{1516}$ Although antidepressants, psychotherapy and alternative therapies have been widely used in the clinical practice, their impact is limited by the rising demand for treatment and the limited resources, both personnel and financial, available for mental healthcare services. ${ }^{1718}$

Depression is preventable. Our previous studies have shown that public health campaigns, which focus on the risk reduction of modifiable risk factors, can significantly prevent the occurrence of 
mental disorders. ${ }^{13}{ }^{19}$ Modifiable risk factors can be used as targets for prevention.

To the best of our knowledge, no previous study has systematically investigated the roles of both psychosocial and environmental risk factors in depression using a longitudinal, population-based study. Public prevention campaigns need to find a target to reduce the risk of depression at a societal level. This longitudinal population-based study was to explore psychosocial and environmental risk factors for incident depression and quantify the effect of risk factors modifications on depression incidence.

\section{METHODS}

\section{Data}

The Montreal South-West Longitudinal Catchment Area Study-Zone d'Épidémiologie Psychiatrique du Sud-Ouest de Montréal (ZEPSOM), is a population-based cohort study of a representative community sample of five neighbourhoods in the South-West sector of Montreal, Canada, which have a combined population of 269720. It is based on an ecological model, which makes it unique. The study was approved by the Douglas Mental Health University Institute Ethics Committee. At the baseline (wave I) of the study, a sample consisted of 2433 individuals randomly selected individuals aged 15-65 years. More details about the study can be found in previous reports. $^{2021}$

\section{Study sample}

Subjects for this study were restricted to those who were depression-free at the wave I (2006/2007). The study was further restricted to those with the complete survey data at waves II and III. This resulted in data being available for 1357 participants at the 2-year follow-up analysis and for 965 participants at the 4-year follow-up analysis. Figure 1 shows the detailed criteria applied to the larger study cohort to obtain the sample analysed here. A lifetime diagnosis of major depressive episode at the wave I was used as an exclusion criteria in order to minimise the influence of recurrent depression on our estimates of the incidence of major depression.

\section{Measures}

Depression diagnoses

The World Mental Health-Composite International Diagnostic Interview (WMH-CIDI), an internationally recognised diagnostic questionnaire for selected mental disorders was used for data collection in the longitudinal study. In addition, the Diagnostic and Statistical Manual of Mental Disorders, 4th edition (DSM-IV) and the International Statistical Classification of Diseases and Related Health Problems, 10th revision (ICD-10) definitions and criteria were used to assess the presence of major depressive disorder, mania, anxiety, panic disorder, social phobia, agoraphobia, alcohol abuse/dependence and drug abuse/dependence. ${ }^{22}$ For this analysis, we had data on major depressive disorder status at baseline, and at the 2-year and 4-year follow-ups. The period from beginning of the study to the first onset of the major depressive disorder indicated the period for developing the disease.

\section{Covariates}

The covariates included sociodemographic factors (age, sex, marital status, income, education, immigrant status), family history of mental disorders, type of drinker (regular drinker, anyone who consumes one or more drinks per month; occasional drinker, anyone who consumes a drink less than once a month; former drinker, a person has not had a drink in at least the last 12 months and abstainer) and community neighbourhood social and ecological characteristics (total crime rate, prevalence of low income, unemployment rate for the population aged 25 years and older, proportion of visible minority population, number of cultural community centres, number of all community organisations, number of all medical clinics, number of mental health-related services and number of physical activity places) in a $500 \mathrm{~m}$ buffer zone for where the survey participants lived.

\section{Statistical analyses}

Comparisons were made between participants selected for this analysis and those who were not included to examine the generalisability of the study sample. We used the modified Poisson regression ${ }^{23}$ to estimate relative risk (RR) for the association between risk factors and incident mental disorders during the study period. Modified Poisson regression analysis has been consistently used in prospective studies to estimate $R R$ with a robust error variance. Covariates with $\mathrm{p}<0.20$ in the univariate analyses were initially considered in the multivariate Poisson regression. The goodness-of-fit was tested. To estimate potential influence of individual risk factors on major depressive disorder, population attributable fractions (PAFs) were used. PAFs represent the percentage of all depression cases exposed to different levels of risk factors that would not have occurred if the exposure had not existed. The PAF was calculated by the following formula based on previous literature ${ }^{24-26}: P A F=\frac{p(R R-1)}{p(R R-1)+1}$, where $p$ is the population incidence of individual risk factor and $R R$ is the relative risk of major depressive disorder given to an individual risk factor holding other covariates constant. We calculated RR based on multiple Poisson regression methods. Finally, the total number of depression cases attributable to risk factors was estimated by multiplying the PAF and the incident cases during the follow-up. All analyses were run using STATA V.12 (StataCorp, 2011).

\section{RESULTS}

\section{Comparison between participants selected in this study and unselected ones}

In comparison with the unselected participants, the analysis sample for both the 2-year and the 4-year follow-ups, contained more younger adults, males, married people (including common-law), people with higher income 


\section{Original catchment area cohort the wave I (2006-2007) $(\mathrm{N}=2433)$}

Missing $(\mathrm{N}=32)$ on depression status, depressed at the wave I (2006-2007) $(\mathrm{N}=587)$

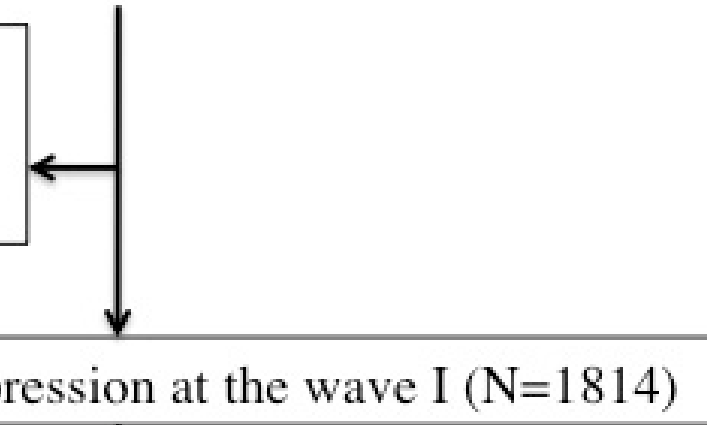

\section{Cohort without depression at the wave I $(\mathrm{N}=1814)$}

Loss follow-up at the wave II ( $\mathrm{N}=457$, including $38 \%$ moved out of study zone, $23 \%$ refused to participate, $38 \%$ impossible to trace, and $1 \%$ other)

Cohort with completed data in 2008/2009 (N=1357)

Loss follow-up at the wave III $(\mathrm{N}=392$, including $46 \%$ moved out of study zone, $26 \%$ refused to participate, $26 \%$ impossible to trace, and $2 \%$ other )

\section{Final analytical sample for the 2-year follow up study $(\mathrm{N}=1357)$}

\footnotetext{
trace, and $2 \%$ other)
}

\section{Final analytical sample for the 4-year follow up $(\mathrm{N}=965)$}

Figure 1 The selection process of the study sample from the Montreal South-West Longitudinal Catchment Area study.

and higher education, immigrants, abstainers and fewer people with a family history of mental health problems $(\mathrm{p}<0.05)$. In addition, compared with those not eligible for this study, the analysis sample tend to live in areas having lower rates of: low income, unemployment for those aged 25 years and older, visible minorities and fewer numbers of cultural community centres, community organisations, medical clinics, mental health-related services and physical activity places $(\mathrm{p}<0.05)$. 


\section{Characteristics of the study population}

For the 2-year follow-up group, the sex ratio was 1:1 (males: $50.3 \%$ vs females: $49.7 \%$ ). In comparison to males, females tend to be older, more likely to be widowed, separated or divorced, poor, more educated, more likely to be occasional/abstainer/former drinkers and have fewer individuals with a family history of mental health problems (see online supplementary appendix 1 ). With respect to community characteristics, males were more likely to live in the places with higher rates of crime, low income, unemployment for those aged 25 years and older, higher proportions of visible minorities and more cultural community centres, but fewer community organisations, medical clinics, mental health-related services and physical activity places $(\mathrm{p}<0.05)$.

For the 4-year follow-up group, there were slightly more females than males $(52.2 \%$ vs $47.8 \%)$. No statistical difference was found between males and females in terms of the crime rate in their neighbourhoods $(p>0.05)$. The rest of characteristics remained the same as what were found in the 2-year follow-up group.

\section{Characteristics associated with depression incidence during the 2-year follow-up}

Multivariate modified Poisson regression was applied to explore the determinants of incident major depressive disorder. The goodness-of-fit was tested for the final model. Table 1 presents characteristics associated with incident major depressive disorder. For those remaining in the cohort after the 2-year period, individual depression risk factors were being younger, female, Caucasian, widowed, separated or divorced, having a family history of mental health problems, being an occasional drinker (vs abstainer) and having less education, were associated with an increased incidence of major depressive disorder. Community/contextual factors significantly associated with incident major depressive disorder included living in the areas with higher unemployment rates, higher proportions of visible minorities, more cultural community centres or community organisations. Those who lived in areas with more physical activity places, more medical clinics, higher rates of low income and crime reported lower rates of incident major depressive disorder during the 2-year follow-up.

We ran different regression models for males and females. Factors including younger age, having a family history of mental health problems, having less education and living in an area with a lower crime rate, lower proportions of people with low income and higher unemployment rate for those aged 25 years and older were consistently related to a higher risk of major depressive disorder. For males, being widowed, separated, divorced, with less education and living in the area with a higher proportion of visible minorities, or more cultural community centres, or mental health-related services, were more likely to develop major depressive disorder. Conversely, females, being an occasional drinker, having a low income, living in the area with more community organisations, were associated with an increased risk of developing major depressive disorder. Table 2 shows the characteristics associated with major depressive disorder for both males and females, separately. Notably, males who lived in areas with more community organisations, medical clinics and physical activity places reported a lower incidence of major depressive disorder. Females, living in areas with higher proportions of visible minorities, more cultural community centres and mental health-related services, were less likely to develop major depressive disorder.

\section{Characteristics associated with the incidence of major depressive disorder during the 4-year follow-up}

The same methods were used to analyse the data for the 4-year follow-up. Table 3 presents characteristics associated with incident major depressive disorder at the 4-year follow-up. For those remaining in the selected sample at the 4-year follow-up, factors significantly associated with an increased risk of developing major depressive disorder including being younger, Caucasian, widowed, separated or divorced, having a family history of mental health problems, being an occasional drinker (vs abstainer), having less education. Also, living in areas with a higher unemployment rate, a lower crime rate, a lower level of income, a higher proportion of visible minorities, more cultural community centres or mental health-related services were associated with an increased incidence of major depressive disorder.

We then explored risk profiles for males and females, separately. Table 4 presents characteristics associated with incident major depressive disorder for both males and females. Individual risk factors included being younger, widowed, separated or divorced, an occasional drinker (vs abstainer) and having less education. For both males and females, community neighbourhood characteristics associated with an increased risk of incident major depressive disorder were living in areas with higher unemployment for those aged 25 years and older, and fewer medical clinics. Males were at higher risk of major depressive disorder if they lived in an area with higher proportions of visible minorities, more cultural community centres or more mental health-related services. Whereas, females had greater risks of major depressive disorder if they were Canadian born, lived in the area with more physical activity places and more community organisations. Notably, females living in areas with more mental health-related services reported a lower incidence of major depressive disorder. For males, living in areas with more physical activity places reduced the risk of developing major depressive disorder.

\section{Number of population potentially influenced by personal modifiable risk factors}

Although we found a number of risk factors including both personal characteristics (modifiable factors, eg, drinking habit, and non-modifiable factors, e.g., family history of mental health problems) and community 
Table 1 Characteristics associated with incident major depressive disorder during the 2-year follow-up (wave II)

\section{People with complete cases} $\mathrm{n}=1212$

\section{Characteristics}

RR, $95 \%$ Cl p Value

Age

0.996 (0.994 to 0.998$)$

$<0.001$

Gender

\begin{tabular}{|c|c|c|}
\hline Males & 1 & \\
\hline Females & $1.176(1.107$ to 1.249$)$ & $<0.001$ \\
\hline \multicolumn{3}{|l|}{ Immigrant status } \\
\hline Immigrant & 1 & \\
\hline Canadian born & 3.250 (2.939 to 3.595$)$ & $<0.001$ \\
\hline \multicolumn{3}{|l|}{ Marital status } \\
\hline Married/common law & 1 & \\
\hline Single & 0.602 (0.538 to 0.673$)$ & $<0.001$ \\
\hline Widowed/separated/divorced & $1.153(1.078$ to 1.234$)$ & $<0.001$ \\
\hline \multicolumn{3}{|l|}{ Family history of mental health problems } \\
\hline No & 1 & \\
\hline Yes & 1.772 (1.668 to 1.882$)$ & $<0.001$ \\
\hline \multicolumn{3}{|l|}{ Type of drinker } \\
\hline Abstainer & 1 & \\
\hline Former & 0.148 (0.117 to 0.186$)$ & $<0.001$ \\
\hline Occasional & 1.277 (1.124 to 1.452$)$ & $<0.001$ \\
\hline Regular & 0.505 (0.443 to 0.575$)$ & $<0.001$ \\
\hline \multicolumn{3}{|l|}{ Education } \\
\hline Postsecondary degree & 1 & \\
\hline Some postsecondary & 1.190 (1.065 to 1.330$)$ & 0.002 \\
\hline Postsecondary & 1.111 (1.017 to 1.215$)$ & 0.020 \\
\hline Less secondary & 0.974 (0.894 to 1.062$)$ & 0.553 \\
\hline \multicolumn{3}{|l|}{ GIS measures in $500 \mathrm{~m}$ buffer zone } \\
\hline Crime rate & 0.996 (0.994 to 0.998$)$ & $<0.001$ \\
\hline Low income rate & 0.979 (0.973 to 0.985$)$ & $<0.001$ \\
\hline Unemployment rate for population aged 25 years and older & $1.110(1.097$ to 1.124$)$ & $<0.001$ \\
\hline Proportion of visible minorities & 1.005 (1.002 to 1.008$)$ & 0.002 \\
\hline No. of cultural community centres & 1.017 (1.004 to 1.031$)$ & 0.013 \\
\hline No. of community organisations & $1.120(1.062$ to 1.181$)$ & $<0.001$ \\
\hline No. of medical clinics & 0.908 (0.861 to 0.958$)$ & $<0.001$ \\
\hline No. of physical activity places & 0.768 (0.734 to 0.803$)$ & $<0.001$ \\
\hline
\end{tabular}

characteristics (number of mental health-related services, etc.), we focus here on modifiable risk factors at the individual level. Drinking habit is the only modifiable risk factor for major depressive disorder consistently evident in the current study.

The cumulative incidence rate of major depressive disorder during the 2-year follow-up was $4.8 \%$ (4.2\% for males and $5.4 \%$ for females), which represented 5318 individuals in the catchment area developed incident major depressive disorder during the 2-year period. We then calculated that $5.1 \%$ (273) of depression cases were potentially attributable to occasional drinking. If the prevalence of occasional drinking could be reduced by $10 \%$, about $50 \%$ (137) of cases were prevented.

The cumulative incidence rate of major depressive disorder during the 4-year follow-up was $6.6 \%$ (5.9\% for males and $7.3 \%$ for females), which represented 5193 individuals in the catchment area developed incident major depressive disorder during the 4-year period. A total of $532(10.2 \%)$ cases were potentially attributable to occasional drinking, and $474(21.5 \%)$ cases of depression were potentially attributable to occasional drinking among males, and $4.18 \%$ (125) cases for females. If the 
Table 2 Characteristics associated with incident major depressive disorder during the 2-year follow-up (wave II) by gender

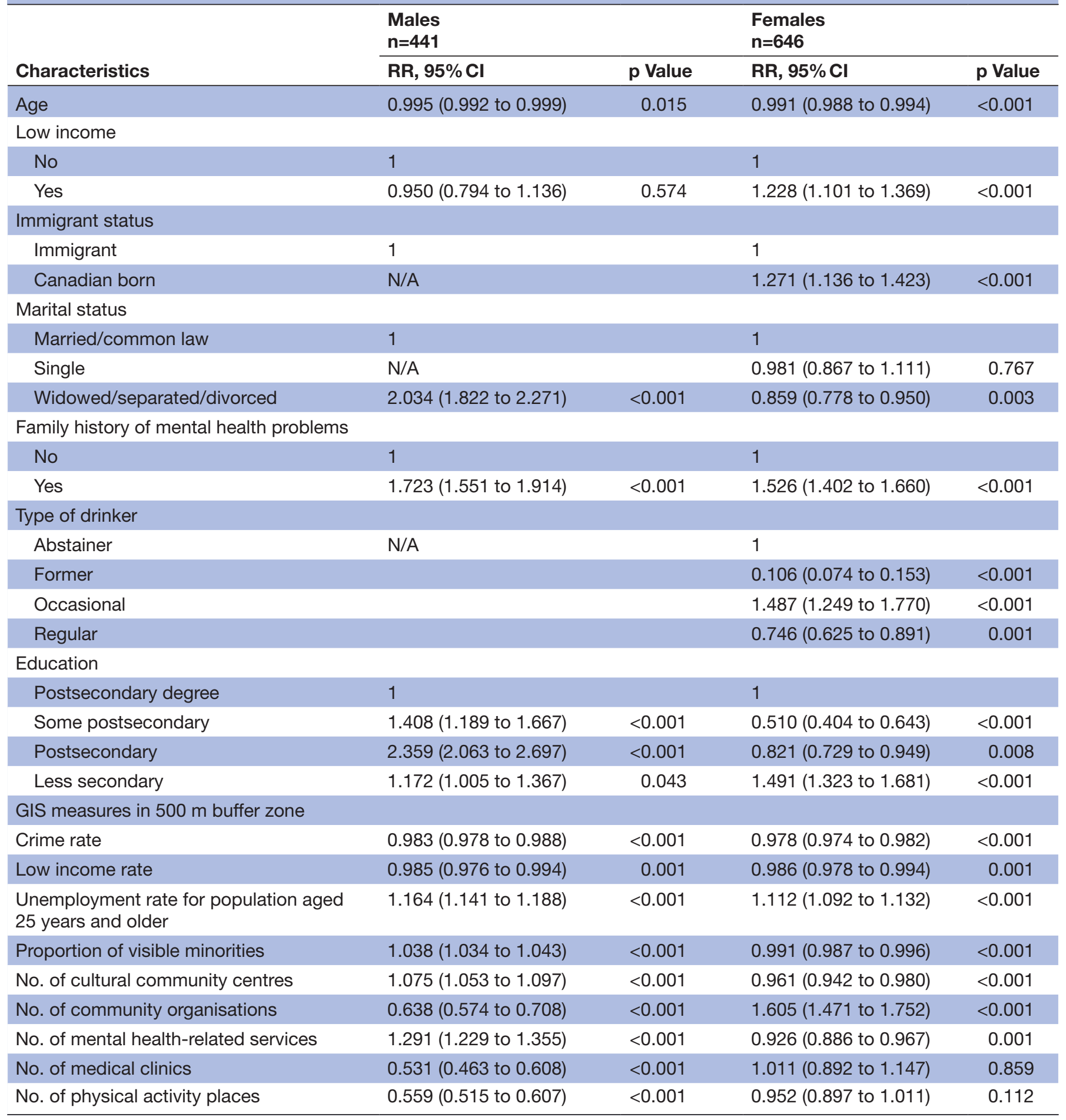

prevalence of occasional drinking could be reduced by $10 \%, 47 \%$ (249) of depression cases would be prevented.

\section{DISCUSSION}

This is a unique study of depression incidence in a longitudinal community cohort, for which both individual and ecological community characteristics were available. We found that the cumulative incidence rate of depression during the 2-year follow-up was $4.8 \%$, and $6.6 \%$ for the 4-year follow-up. Being a younger adult, female, widowed, separated or divorced, Caucasian, poor, occasional drinker (vs abstainer), having a family history of mental health problems, having less education and living in areas with a higher unemployment rate, more visible minorities, more cultural community centres and community organisations, were consistently associated with the increased risk of incident major depressive disorder. Although only $5.1 \%$ of depression incidence was potentially attributable 
Table 3 Characteristics associated with incident major depressive disorder during the 4-year follow-up (wave III)

\section{Data with complete case}

$\mathrm{n}=877$

\section{Characteristics}

Age

$\begin{array}{ll}\mathbf{R R}, \mathbf{9 5 \%} \mathbf{C l} & \mathbf{p} \text { Value } \\ 0.992(0.990 \text { to } 0.994) & <0.001\end{array}$

Immigrant status

$\begin{array}{lll}\text { Immigrant } & 1 & \\ \text { Canadian born } & 3.117(2.845 \text { to } 3.415)\end{array}$

Marital status

Married/common law 1

Single

Widowed/separated/divorced

0.550 (0.499 to 0.608$)$

$<0.001$

$1.277(1.204$ to 1.354$) \quad<0.001$

Family history of mental health problems

No

Yes

Type of drinker

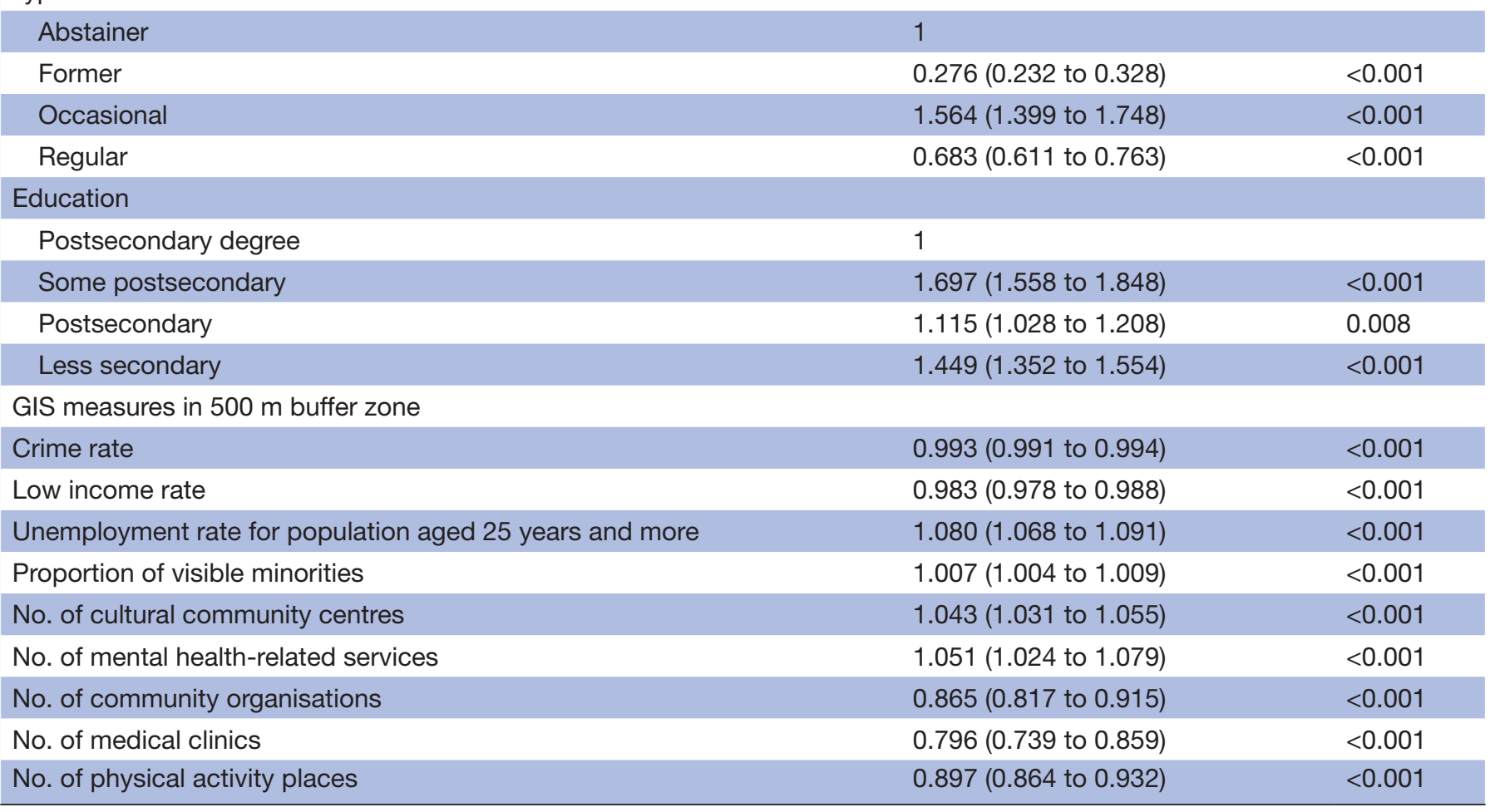

to occasional drinking at the 2-year follow-up, the attribution of occasional drinking increased to $10.2 \%$ at the 4-year follow-up. Furthermore, a $10 \%$ reduction in the prevalence of occasional drinking among this population could potentially prevent half of incident depression cases.

There is a lack of information on the cumulative incidence of major depressive disorder. Comparisons of the cumulative incidence are also restricted by different scales or questionnaires used to identify major depressive disorder. A previous study in a national Canadian longitudinal sample reported a 16-year incidence of major depressive disorder was $12.1 \%{ }^{19}$ In this current analysis, we found the 2-year cumulative incidence of major depressive disorder was $4.8 \%$, and $6.6 \%$ at the 4 -year follow-up, indicating that major depressive disorder is a critical public mental health problem. It is not surprising that the risk of major depressive disorder increases as the observational time lengthens. A straightforward explanation is that the longer observational time increases the possibility of having more risk exposures (ie, stressful life events, occurrence of other comorbidities, etc), which contribute to develop of the disease.

People who are younger, female, having a lower income and having a family history of mental health problems, have been consistently found to be at an increased risk of having major depressive disorder. ${ }^{1927}$ We also found immigrants (compared with Canadian born) had a lower 
Table 4 Characteristics associated with incident major depressive disorder during the 4-year follow-up (wave III) for those with complete cases

\begin{tabular}{|c|c|c|c|c|}
\hline \multirow[b]{2}{*}{ Characteristics } & \multicolumn{2}{|l|}{$\begin{array}{l}\text { Males } \\
\mathrm{n}=327\end{array}$} & \multicolumn{2}{|l|}{$\begin{array}{l}\text { Females } \\
n=550\end{array}$} \\
\hline & RR, 95\% Cl & p Value & $\mathrm{RR}, \mathbf{9 5} \% \mathrm{Cl}$ & p Value \\
\hline Age & 0.985 (0.982 to 0.988$)$ & $<0.001$ & 0.992 (0.989 to 0.995$)$ & $<0.001$ \\
\hline \multicolumn{5}{|l|}{ Immigrant status } \\
\hline Immigrant & & & 1 & \\
\hline Canadian born & $\mathrm{N} / \mathrm{A}$ & & 1.274 (1.156 to 1.404$)$ & $<0.001$ \\
\hline \multicolumn{5}{|l|}{ Marital status } \\
\hline Married/common law & 1 & & 1 & \\
\hline Single & N/A & & $0.893(0.802$ to 0.994$)$ & 0.038 \\
\hline Widowed/separated/divorced & 1.469 (1.338 to 1.612$)$ & $<0.001$ & 1.166 (1.075 to 1.265$)$ & $<0.001$ \\
\hline \multicolumn{5}{|l|}{ Family history of mental health problems } \\
\hline No & 1 & & 1 & \\
\hline Yes & 2.774 (2.556 to 3.011$)$ & $<0.001$ & 1.530 (1.424 to 1.644$)$ & $<0.001$ \\
\hline \multicolumn{5}{|l|}{ Type of drinker } \\
\hline Abstainer & 1 & & 1 & \\
\hline Former & $0.255(0.178$ to 0.365$)$ & $<0.001$ & $0.213(0.169$ to 0.269$)$ & $<0.001$ \\
\hline Occasional & 2.618 (1.929 to 3.555$)$ & $<0.001$ & $1.187(1.045$ to 1.349$)$ & 0.008 \\
\hline Regular & $0.452(0.332$ to 0.615$)$ & $<0.001$ & 0.747 (0.657 to 0.849$)$ & $<0.001$ \\
\hline \multicolumn{5}{|l|}{ Education } \\
\hline Postsecondary degree & 1 & & 1 & \\
\hline Some postsecondary & $1.747(1.548$ to 1.971$)$ & $<0.001$ & 1.436 (1.256 to 1.643$)$ & $<0.001$ \\
\hline Postsecondary & $1.407(1.243$ to 1.591$)$ & $<0.001$ & 1.079 (0.961 to 1.210$)$ & 0.198 \\
\hline Less secondary & $1.040(0.930$ to 1.165$)$ & 0.490 & $1.629(1.478$ to 1.796$)$ & $<0.001$ \\
\hline \multicolumn{5}{|l|}{ GIS measures in $500 \mathrm{~m}$ buffer zone } \\
\hline Crime rate & 0.993 (0.990 to 0.996$)$ & $<0.001$ & 0.987 (0.984 to 0.991$)$ & $<0.001$ \\
\hline Prevalence of low income & 0.976 (0.968 to 0.985$)$ & $<0.001$ & 0.998 (0.991 to 1.005$)$ & 0.574 \\
\hline $\begin{array}{l}\text { Unemployment rate for population aged } \\
25 \text { years and more }\end{array}$ & 1.141 (1.121 to 1.162$)$ & $<0.001$ & 1.054 (1.038 to 1.071$)$ & $<0.001$ \\
\hline Proportion of visible minority population & $1.054(1.050$ to 1.059$)$ & $<0.001$ & 0.984 (0.980 to 0.988$)$ & $<0.001$ \\
\hline No. of cultural community centres & 1.077 (1.058 to 1.097$)$ & $<0.001$ & 1.006 (0.991 to 1.022$)$ & 0.414 \\
\hline No. of mental health-related services & $1.303(1.249$ to 1.360$)$ & $<0.001$ & $0.876(0.843$ to 0.910$)$ & $<0.001$ \\
\hline No. of community organisations & $0.447(0.408$ to 0.490$)$ & $<0.001$ & 1.408 (1.301 to 1.524$)$ & $<0.001$ \\
\hline No. of medical clinics & 0.508 (0.453 to 0.570$)$ & $<0.001$ & 0.944 (0.844 to 1.055$)$ & $<0.001$ \\
\hline No. of physical activity places & 0.743 (0.694 to 0.795$)$ & $<0.001$ & $1.081(1.030$ to 1.135$)$ & $<0.001$ \\
\hline
\end{tabular}

risk of having depression. ${ }^{28}{ }^{29}$ In Canada, the pre-entry medical examination policy may be one of the reasons for this phenomenon. In addition, we identified several neighbourhood (contextual) characteristics associated with major depressive disorder. Researchers have investigated the role of neighbourhood in mental health. Although it is not completely consistent, a number of studies have found that neighbourhoods with poor-quality housing, poverty and higher unemployment rates are associated with higher risk of major depressive disorder. ${ }^{30}{ }^{31}$ Stress plays a role in the relationships between neighbourhood characteristics and depression. Researchers hypothesised that the role of neighbourhood characteristics in incident major depressive disorder by (1) increasing the level of daily stress, (2) influencing on the vulnerability to depression and (3) interfering with the formation of bonds among people. ${ }^{32}$ We found people living areas with higher unemployment were more likely to develop incident major depressive disorder. This is consistent with the theoretical explanations of neighbourhood's role in major depressive disorder. We also found that those living in an area with higher proportion of visible minorities, more cultural community centres and more mental health-related services reported a higher incidence of 
major depressive disorder. This seems counterfactual with what other studies have shown about more resources in the neighbourhood decrease the risk of major depressive disorder. One explanation of this finding is that people from different ethnic groups have different vulnerability for the disease, and discrimination due to minority status could also increase risk. ${ }^{33}$ Alternatively, the increase in mental health-related community services might reflect a greater need, or perceived need, in theses areas. The availability of mental health service is critical to help identify and treat people suffering from major depressive disorder. Areas with more mental health services are associated with better education and knowledge of mental health problems among people who live in these areas. Those cases may be more likely to be identified in these areas. The measurements and operationalisation of definitions of geospatial community characteristics may also differ between studies. There is a need to consider these differences in making comparisons.

The literature reports significant differences in the determinants associated with major depressive disorder between males and females. ${ }^{34}$ We found the same phenomenon. Males living in areas with more physical activity places reported a lower rate of major depressive disorder, but this finding does not apply for females. Although the mechanism of the discrepancy is difficult to understand due to many domains involved, including biological, psychological and sociocultural influences, our finding reinforces the importance of recognising the gender difference in major depressive disorder, and warrants gender-specific prevention programmes for major depressive disorder.

Inconsistent findings regarding the relationship between alcohol consumption and major depressive disorder have been reported in the literature, ${ }^{356}$ partially due to the measurements of alcohol consumption (frequency of drinking behaviour and/or quantity per occasion) and major depressive disorder. One study on quantity per occasion suggested that major depressive disorder was primarily related to drinking large quantities per occasion, and this effect was stronger for females than for males. ${ }^{35}$ Since we did not have measures on quantity per occasion, direct comparison to this findings was not possible.

In terms of drinking frequency and depression, one study suggested the U-shape relationships of alcohol consumption and major depressive disorder, because abstainers or heavy drinkers were associated with many disadvantaged factors, including low-status occupations, less education, current financial hardship, poor social support and many of these characteristics are related to major depressive disorder ${ }^{37}$ However, in this study after adjusting other covariates, we found 'occasional drinkers' had higher rates of incident major depressive disorders compared with abstainers.

Occasional drinking (compared with non-drinking) was the only modifiable risk factor at an individual level. It explained around 5\% 10\% of incident major depressive disorders. From public health perspectives, occasional drinking could be a target for public prevention programmes. We also identified few neighbourhood characteristics associated with depression. However, it can be more challenging to modify these neighbourhood characteristics. A cost-effectiveness analysis of prevention efforts is also advised.

\section{Strengths and limitations}

The primary strength of our study is we used relatively large longitudinal population-based study to quantity the potential effects of risk factor modifications on the incidence of major depressive disorder. We examined the effect of individual risk factors as well as neighbourhood characteristics. The risk and contextual factors were analysed in multivariate models. While we have strove to deliver reliable results, there are several limitations to this study: (1) only individuals who completed all the three waves of data collection were included in the analysis. Compared with those without complete data, our sample had statistically different characteristics, which were also associated with major depressive disorder. The generalisability of our findings is restricted; (2) our sample was not representative for the whole survey sample. There was a significant attrition. ${ }^{38}$ Those survey participants, who did not complete all the follow-up assessments, had an increased risk of major depressive disorder compared with our sample. The cumulative incidence rates reported in this study may be underestimated; (3) this is an secondary analysis of data already collected, therefore we are limited in the variables and interactions we could explore, for example, the variable 'type of drinker' only codes for regular drinker, occasional drinker, former drinker and abstainer. There are more useful ways to characterise drinking behaviour. However, because data were already recorded, we are restricted in terms of defining variables; (4) the cause of major depression is complex. It is difficult to know how much we could achieve on the disease reduction, when a single risk factor is removed or reduced in prevalence.

Acknowledgements The authors would like to thank the researchers, interviewers and participants in the Zone d'Épidémiologie Psychiatrique du Sud-Ouest de Montréal study.

Contributors XM took part in concept, design, statistical analyses, drafting manuscript and interpretation of results. JC was responsible for design the Zone d'Épidémiologie Psychiatrique du Sud-Ouest de Montréal (ZEPSOM) study, support for statistical analyses. AB and GT were co-investigators of the ZEPSOM study. AL and $C D$ support the statistical analysis and critically review the manuscript.

Funding The Zone d'Épidémiologie Psychiatrique du Sud-Ouest de Montréal study was funded by the Canadian Institute of Health Research (CTP-79839), (PJT148845). Meng received the start-up fund from Douglas Mental Health University Institute.

\section{Competing interests None declared.}

Ethics approval Douglas Mental Health University Institute Ethics Committee. Provenance and peer review Not commissioned; externally peer reviewed.

Data sharing statement The Zone d'Épidémiologie Psychiatrique du Sud-Ouest de Montréal (ZEPSOM) study is currently continuing in survey data and biological sample data collection, consequently, for now only members of the ZEPSOM study team have access the data. 
Open Access This is an Open Access article distributed in accordance with the Creative Commons Attribution Non Commercial (CC BY-NC 4.0) license, which permits others to distribute, remix, adapt, build upon this work non-commercially, and license their derivative works on different terms, provided the original work is properly cited and the use is non-commercial. See: http://creativecommons.org/ licenses/by-nc/4.0/

(c) Article author(s) (or their employer(s) unless otherwise stated in the text of the article) 2017. All rights reserved. No commercial use is permitted unless otherwise expressly granted.

\section{REFERENCES}

1. Ferrari AJ, Charlson FJ, Norman RE, et al. Burden of depressive disorders by country, sex, age, and year: findings from the global burden of disease study 2010. PLoS Med 2013;10:e1001547.

2. Murray CJ, Vos T, Lozano R, et al. Disability-adjusted life years (DALYs) for 291 diseases and injuries in 21 regions, 1990-2010: a systematic analysis for the Global Burden of Disease Study 2010. Lancet 2012;380:2197-223.

3. Crystal S, Sambamoorthi U, Walkup JT, et al. Diagnosis and treatment of depression in the elderly medicare population: predictors, disparities, and trends. J Am Geriatr Soc 2003;51:1718-28.

4. WHO. Promoting Mental Health: concepts, emerging evidence, practice (Summary Report). Geneva: World Health Organization; 2004.

5. Walder DJ, Faraone SV, Glatt SJ, et al. Genetic liability, prenatal health, stress and family environment: risk factors in the harvard adolescent family high risk for schizophrenia study. Schizophr Res 2014;157:142-8.

6. Walder DJ, Laplante DP, Sousa-Pires A, et al. Prenatal maternal stress predicts autism traits in 61/2 year-old children: Project lce Storm. Psychiatry Res 2014;219:353-60.

7. Waxman J, Van Lieshout RJ, Schmidt LA. Early adversity and mental health: linking extremely low birth weight, emotion regulation, and internalizing disorders. Curr Pediatr Rev 2014;10:208-15.

8. Colman I, Murray J, Abbott RA, et al. Outcomes of conduct problems in adolescence: 40 year follow-up of national cohort. BMJ 2009;338:a2981.

9. Kessler RC, Amminger GP, Aguilar-Gaxiola S, et al. Age of onset of mental disorders: a review of recent literature. Curr Opin Psychiatry 2007;20:359-64.

10. Salkever DS, Gibbons B, Drake RE, et al. Increasing earnings of social security disability income beneficiaries with serious mental disorder. J Ment Health Policy Econ 2014;17:75-90.

11. Pompili M, Innamorati M, Di Vittorio C, et al. Unemployment as a risk factor for completed suicide: a psychological autopsy study. Arch Suicide Res 2014;18:181-92.

12. He Q, Yang L, Shi S, et al. Smoking and major depressive disorder in chinese women. PLoS One 2014;9:e106287.

13. Meng $X$, D'Arcy $C$. The projected effect of increasing physical activity on reducing the prevalence of common mental disorders among canadian men and women: a national population-based community study. Prev Med 2013;56:59-63.

14. Rawana JS, Morgan AS, Nguyen $\mathrm{H}$, et al. The relation between eating- and weight-related disturbances and depression in adolescence: a review. Clin Child Fam Psychol Rev 2010;13:213-30.

15. Fu TS, Lee CS, Gunnell D, et al. Changing trends in the prevalence of common mental disorders in Taiwan: a 20 -year repeated crosssectional survey. Lancet 2013;381:235-41.

16. Smith RP1, Larkin GL, Southwick SM. Trends in U.S. emergency department visits for anxiety-related mental health conditions, 19922001. J Clin Psychiatry 2008;69:286-94.

17. Fournier JC, DeRubeis RJ, Hollon SD, et al. Antidepressant drug effects and depression severity: a patient-level meta-analysis. JAMA 2010;303:47-53.
18. Weissman MM, Verdeli H, Gameroff MJ, et al. National survey of psychotherapy training in psychiatry, psychology, and social work. Arch Gen Psychiatry 2006;63:925-34.

19. Meng X, D'Arcy $C$. The projected effect of risk factor reduction on major depression incidence: a 16-year longitudinal Canadian cohort of the National Population Health Survey. J Affect Disord 2014;158:56-61.

20. Caron J, Fleury MJ, Perreault M, et al. Prevalence of psychological distress and mental disorders, and use of mental health services in the epidemiological catchment area of Montreal South-West. BMC Psychiatry 2012;12:183.

21. Fleury MJ, Grenier G, Bamvita JM, et al. Comprehensive determinants of health service utilisation for mental health reasons in a Canadian catchment area. Int J Equity Health 2012;11:20.

22. Streiner DL, Cairney J, Lesage A. Psychiatric epidemiology in Canada and the CCHS study. Can J Psychiatry 2005;50:571-2.

23. Zou G. A modified poisson regression approach to prospective studies with binary data. Am J Epidemiol 2004;159:702-6.

24. Barnes DE, Yaffe K. The projected effect of risk factor reduction on Alzheimer's disease prevalence. Lancet Neurol 2011;10:819-28.

25. Rockhill B, Newman B, Weinberg C. Use and misuse of population attributable fractions. Am J Public Health 1998;88:15-19.

26. Sareen J, Belik SL, Afifi TO, et al. Canadian military personnel's population attributable fractions of mental disorders and mental health service use associated with combat and peacekeeping operations. Am J Public Health 2008;98:2191-8.

27. Scott KM, Oakley Browne MA, Elisabeth Wells J. Prevalence, impairment and severity of 12-month DSM-IV major depressive episodes in Te Rau Hinengaro: New Zealand Mental Health Survey 2003/4. Aust N Z J Psychiatry 2010;44:750-8.

28. Meng $X, D^{\prime}$ Arcy $C$. Common and unique risk factors and comorbidity for 12-month mood and anxiety disorders among Canadians. Can J Psychiatry 2012;57:479-87.

29. Riolo SA, Nguyen TA, Greden JF, et al. Prevalence of depression by race/ethnicity: findings from the National Health and Nutrition Examination Survey III. Am J Public Health 2005;95:998-1000.

30. Echeverría S, Diez-Roux AV, Shea S, et al. Associations of neighborhood problems and neighborhood social cohesion with mental health and health behaviors: the Multi-Ethnic Study of Atherosclerosis. Health Place 2008;14:853-65.

31. Julien D, Richard L, Gauvin L, et al. Neighborhood characteristics and depressive mood among older adults: an integrative review. Int Psychogeriatr 2012;24:1207-25.

32. Cutrona CE, Wallace G, Wesner KA, et al. And depression: an examination of stress processes. Curr Dir Psychol Sci 2006;15:188-92.

33. Budhwani H, Hearld KR, Chavez-Yenter D. Depression in racial and ethnic minorities: the impact of Nativity and Discrimination. J Racial Ethn Health Disparities 2015;2:34-42.

34. Piccinelli M, Wilkinson G. Gender differences in depression. critical review. Br J Psychiatry 2000;177:486-92.

35. Graham K, Massak A, Demers A, et al. Does the association between alcohol consumption and depression depend on how they are measured? Alcohol Clin Exp Res 2007;31:78-88.

36. Powers JR, Young AF. Longitudinal analysis of alcohol consumption and health of middle-aged women in Australia. Addiction 2008;103:424-32.

37. Rodgers $B$, Korten AE, Jorm AF, et al. Risk factors for depression and anxiety in abstainers, moderate drinkers and heavy drinkers. Addiction 2000;95:1833-45.

38. Geerlings SW, Beekman AT, Deeg DJ, et al. Duration and severity of depression predict mortality in older adults in the community. Psychol Med 2002;32:609-18.

39. White J, Zaninotto P, Walters K, et al. Duration of depressive symptoms and mortality risk: the English Longitudinal Study of Ageing (ELSA). Br J Psychiatry 2016;208:337-42. 